\title{
Editorial: Why an Issue on the New Public Health?
}

\author{
Theodore H Tulchinsky, ${ }^{1}$ \\ Helen Ann Halpin ${ }^{2}$
}

In this inaugural issue of the revived journal, Public Health Reviews, we seek to address a wide audience from the myriad disciplines that comprise the workforce of public health. In this effort, we hope to reach public health educators, researchers, students, policy makers, and practitioners worldwide with evidence-based theoretical and experiential knowledge. Applied nationally and internationally, public health has enormous global potential to save lives and improve quality of life if applied equitably throughout the world. The inaugural issue is therefore devoted to the New Public Health, as the basis for improving population health globally.

The central idea behind this issue is to focus on some of the major challenges and possibilities for improving health in the coming decades. The New Public Health involves the interdependence of traditional local, state or provincial, national, and global public health initiatives and their societal and political contexts. European societies, as others, face the challenges of ageing populations, increasing costs and rising public and individual expectations. At the same time, there are many social, regional, and transnational disparities. ${ }^{1,2}$

The New Public Health addresses traditional aspects of public health, as well as the great potential for prevention-oriented healthcare systems. The New Public Health seeks to safeguard and improve individual health in the context of social and economic disparities that exist in varying degrees in all countries and regions. Furthering the New Public Health implies crossfertilization between public health protection, health promotion, disease prevention, health maintenance, and environmental health in the context of improvement of societal, economic, industrial and community habitation policies. Management of health systems and resource allocation are crucial to setting priorities in prevention, and the effective organization and

\footnotetext{
${ }^{1}$ Braun School Public Health and Community Medicine, Hebrew University, Jerusalem; Deputy Editor, Public Health Reviews.

${ }^{2}$ University of California, Berkeley; Deputy Editor, Public Health Reviews.
} 
provision of health services are a cornerstone of society's responsibility for the health and well-being of the population.

The New Public Health is not a new vision of what health should be; it is a strategic and equitable application of current best practices across the broadest aspects of social policy, public health, and healthcare systems. Ultimately, the New Public Health relies on the adoption of effective policies and programs based on the cumulative experience and available scientific evidence. Such programs and policies must be targeted to individuals, to groups at special risk, to communities, and to societies across the globe.

In this issue, we seek to present the interdependence of social and health policy with examples illustrating the interconnectedness of healthcare systems issues. The topics included are not encyclopedic of all the vital issues facing public health systems in the $21^{\text {st }}$ century. Many of those that are not included in this first issue will be addressed in later issues of the journal. Accordingly, we start with the application of science to public health practice, as in the case of Helicobacter pylori, and we move on through health systems, organization of public health, chronic diseases, micronutrient deficiencies and infectious diseases.

In this issue, we include:

Preface, ${ }^{3}$ and Foreword: Reminiscences of Helicobacter pylori. ${ }^{4}$ Respectively by Theodore Tulchinsky, Antoine Flahault, and Robin Warren (Nobel Prize 2005, Western Australia), who relates his experience of scientific discovery that was ultimately embraced by medical and public health practitioners and policy makers. This fascinating historical account provides a vivid example of translating science into practice with major impacts on population health and health services.

Editorial: Why a journal called Public Health Reviews? ${ }^{5}$ Antoine Flahault and Linda Fried present the renewal of this journal with a wider international scope, reaching out to a European and worldwide readership.

What is the "New Public Health"? ${ }^{6}$ Theodore Tulchinsky and Elena Varavikova explore the parameters of the New Public Health and how it has evolved and continues to evolve with recent advances in science, technology, legislation, and management with demonstrated success in improving individual and population health.

Threats to global health and opportunities for change: a new global health. ${ }^{7}$ Ulrich Laaser and Leon Epstein address health inequalities, successes, and failures in the implementation of public health practices and policies to achieve the health-related Millennium Development Goals.

Communicable diseases: achievements and challenges for public health. ${ }^{8}$ Ursula Schlipköter and Antoine Flahault review the progress made 
within the sphere of infectious disease control and prevention, including notable achievements such as antibiotics and vaccines, the current state of infectious disease issues such as endemics, epidemics, and pandemics, and what they hope will be achieved in the future.

Chronic disease and prevention. ${ }^{9}$ Helen Halpin, Maria MoralesSuárez-Varela, and Jose Martin Moreno review the leading causes of chronic disease morbidity and mortality, including the linkages between infectious and chronic disease. Public policy and programmatic responses to chronic disease prevention targeting the individual, community, and society levels that have been demonstrated to be effective in reducing the burden of these diseases in a population are reviewed.

The political face of public health. ${ }^{10}$ Lawrence Brown discusses the priority and place of public health in health policy and the need for changes in public policy to address inequities and the full capacity for prevention to improve health status in the US.

A framework for public health in the United States. ${ }^{11}$ Jonathan Fielding, Steven Teutsch and Lester Breslow describe how governmental and non-governmental public health activities work in parallel in the United States to address a widening and state-of-the-art range of activities, interventions, and programs.

United States innovations in healthcare delivery. ${ }^{12}$ Stephen Shortell, Robin Gillies, and Frances Wu describe the context and innovations of the US health system with implications for the future evolution of health systems in the US and other countries. They review the evidence for integrated health systems, their performance, the challenges involved, and the factors that might promote greater adoption and diffusion of successful models. The role played by the political system and its associated culture, structural barriers, resources, incentive alignment, and leadership is also explored.

Public health in Europe: power, politics, and where next? ${ }^{13}$ David Stuckler, Sanjay Basu, and Martin McKee address health inequalities across Europe, as well as within countries with national health systems based on social solidarity, in the context of the political economy, social determinants of health, and the role of medical care.

Micronutrient issues in public health. ${ }^{14-17}$ Theodore Tulchinsky, Gail Harrison, Michael Holick, and Godfrey Oakley address important flagship issues in public health nutrition, especially fortification of basic foods, focusing on folic acid, vitamin B12, and vitamin D deficiency. The advantages and shortcomings of supplementation and fortification programs are reviewed. 
Workforce resources for health in developing countries. ${ }^{18}$ Shrikant Bangdiwala, Sharon Fonn, Osegbeaghe Okoye and Stephen Tollman describe the issues related to severe shortages and misdistribution of health professionals in sub-Saharan Africa. The potential and need for both mid-level and community health workers, and the need for training capacity for public health professionals are discussed.

Influenza pandemics past and future. ${ }^{19}$ Antoine Flahault and Patrick Zylberman examine the recent influenza A (H1N1) pandemic and previous pandemics through a historical lens, also providing implications for policy and public health systems.

Consistent with the policy and goals of the Editorial Board, the articles in this issue do not present new scientific research, but review the current state of knowledge and practice for the selected topics addressed. Our objective is to promote a widened awareness of issues concerning current public health policy and health systems management of a New Public Health. We seek to promote the translation of scientific evidence from research and best practice to reduce health disparities across Europe and globally. ${ }^{20}$

We hope this endeavor will encourage more effective, efficient, and equitable policies and programs, and lead to a more rapid application of science in all the social, political, and biomedical aspects of public health practice in the wider context of a New Public Health.

\section{REFERENCES}

1. World Health Organization. Commission on Social Determinants of Health Final Report. WHO, Geneva, 2008. Available from URL: http://www.who. int/social_determinants/thecommission/finalreport/en/index.html (Accessed 18 April, 2010).

2. Commission of the European Communities. Communication from the Commission to the European Parliament, the Council, the European Economic and Social Committee of the Regions Solidarity in Health: reducing health inequalities in the EU. Brussels 20.10.2009. Available from URL: http://ec.europa.eu/ health/ph_determinants/socio_economics/documents/com2009_en.pdf (Accessed 18 April, 2010).

3. Flahault A, Tulchinsky TH. Preface to reminiscences on Helicobacter pylori. Public Health Reviews 2010;32:7-14.

4. Warren JR. Reminiscences on Helicobacter pylori. Public Health Reviews 2010;32:10-14.

5. Flahault A, Fried L [editorial]. Why a new journal called Public Health Reviews? Public Health Reviews 2010;32:15-17. 
6. Tulchinsky TH, Varavikova EA. What is the "New Public Health"? Public Health Reviews 2010;32:25-53.

7. Laaser U, Epstein L. Threats to global health and opportunities for change: a new global health. Public Health Reviews 2010;32:54-89.

8. Schlipköter U, Flahault A. Communicable diseases: achievements and challenges for public health. Public Health Reviews 2010;32:90-119.

9. Halpin HA, Morales-Suárez-Varela MM, Martin-Moreno JM. Chronic disease prevention and the New Public Health. Public Health Reviews 2010;32:120154.

10. Brown LD. The political face of public health. Public Health Reviews 2010; 32:155-173.

11. Fielding JE, Teutsch S, Breslow L. A framework for public health in the United States. Public Health Reviews 2010;32:174-189.

12. Shortell SM, Gillies R, Wu F. United States innovations in healthcare delivery. Public Health Reviews 2010;32:190-212.

13. Stuckler D, Basu S, McKee M. Public health in Europe: power, politics, and where next? Public Health Reviews 2010;32:213-242.

14. TH Tulchinsky. Micronutrient deficiency conditions: global health issues. Public Health Reviews 2010;32:243-255.

15. Harrison GG. Public health interventions to combat micronutrient deficiencies. Public Health Reviews 2010;32:256-266.

16. Oakley GP. Folic acid and vitamin B12 fortification of flour: a global basic food security requirement. Public Health Reviews 2010;32:284-295.

17. Holick MF. The vitamin D deficiency pandemic: a forgotten hormone important for health. Public Health Reviews 2010;32:267-283.

18. Bangdiwala SI, Fonn S, Okoye O, Tollman S. Workforce resources for health in developing countries. Public Health Reviews 2010;32:296-318.

19. Flahault A, Zylberman P. Influenza pandemics past and future. Public Health Reviews 2010;32:319-340.

20. Koh H, Oppenheimer SC, Maasin-Short SB, Emmons K, Geller A. Translating research evidence into practice to reduce health disparities: a social determinants approach. Am J Public Health. 2010;100:S72-S80. 